\title{
Desain struktur kawat penyangga ambalan
}

\author{
Centaury Harjani ${ }^{1 *}$, Christmastuti Nur ${ }^{1}$ \\ ${ }^{1}$ Program Studi Desain Produk, Universitas Kristen Duta Wacana, Yogyakarta, Indonesia
}

\begin{abstract}
Wall shelf is one of furniture that is widely used nowadays. A wall shelf which is designed to utilize the vertical area of the house becomes a favorable choice because of its minimalist and space saving design. The wall shelves design on the market usually has a metal retaining frame. Certain designs use L-brackets support structures, however, some of them do not use it at all. Most L-brackets are made of metal material from industrial mass production. Actually, design of a wall shelf can be made using a wire retaining structure. Wire material can be used as a support structure that is able to withstand loads. This research used experimental method to explore several supporting structure designs of wire material. Manual techniques such as twisting technique, coiling technique, and bending technique were combined to increase strength of the wire. Various exploration results were tested to determine firmest structure with the most efficient material. This article is expected to revive the tradition of craftsmanship and to inspire young designers to be creative in developing wire product design.
\end{abstract}

Key words: wall shelf, structure design, wire design, wire structure

\begin{abstract}
Abstrak
Ambalan menjadi salah satu furnitur yang banyak digunakan saat ini. Ambalan yang didesain memanfaatkan area vertikal dinding rumah menjadi pilihan karena desainnya yang minimalis dan hemat ruang. Desain ambalan yang ada dipasaran biasanya memiliki rangka penahan dari logam. Ada yang menggunakan struktur penyangga siku dan ada pula yang tanpa struktur penyangga siku. Rata-rata struktur penyangga siku pada ambalan terbuat dari material logam hasil produksi massal dari suatu industri. Sesungguhnya desain suatu ambalan dapat dibuat dengan menggunakan struktur penahan dari kawat. Material kawat dapat didesain menjadi struktur penyangga yang mampu menahan beban. Penelitian ini menggunakan metode eksperimen dalam mengeksplorasi beberapa desain struktur penyangga dari material kawat. Penggunaan teknik manual seperti puntir, lilit, dan bengkok dipadukan dalam meningkatkan kekuatan kawat. Berbagai hasil eksplorasi kemudian diuji untuk menentukan bentuk struktur yang paling kokoh dengan material yang paling efisien. Tulisan ini diharapkan dapat menghidupkan kembali tradisi bekerja dengan tangan serta menginspirasi calon desainer muda dalam berkreasi mengembangkan desain produk berbahan kawat.
\end{abstract}

Kata kunci: ambalan, desain struktur, desain kawat, struktur kawat

\section{Pendahuluan}

Area dinding vertikal merupakan salah satu bagian ruang yang dapat dijadikan sebagai sasaran strategi untuk melakukan penghematan space di dalam suatu hunian. Astuti dan Kusno mengatakan bahwa rak (ambalan) merupakan salah satu produk interior yang banyak menjadi pilihan (Astuti \& Kusno, 2014). Menurut mereka pula, ambalan memiliki beragam bentuk, namun yang paling sederhana dan dapat menampung banyak barang adalah bentuk datar memanjang. Berdasarkan struktur penyangganya, ada dua macam ambalan yaitu ambalan dengan siku penahan dan ambalan dengan penahan yang tersembunyi (angkur). Gambar 1 memperlihatkan berbagai desain ambalan dengan angkur. Sedangkan desain ambalan dengan siku penahan diperlihatkan dalam Gambar 2.

Artikel ini membahas ambalan dengan siku penahan dalam berbagai desain dengan tujuan untuk melihat struktur konstruksi penahan ambalan yang ideal. Desain struktur yang dibahas merupakan hasil dari mata kuliah Desain Produk 1 yang berisi materi tentang struktur dan konstruksi dengan fungsi sederhana, yaitu penahan ambalan. Beberapa prototipe desain karya mahasiswa desain produk ini diuji dengan beban tertentu dan dibandingkan satu

\footnotetext{
* Corresponding author Tel : +62-274-563929 (ext.525) ; fax +62-274-513235 ; e-mail : centaury_h@staff.ukdw.ac.id
} 
dengan yang lain. Pembuatan prototipe itu sendiri merupakan salah satu tahapan dalam proses desain yang bertujuan untuk mengkomunikasikan desain yang baru kepada pihak-pihak yang relevan dan mengujinya (Jayadi \& Prasetya, 2017). Hasil ulasan dari perbandingan desain-desain yang ada tersebut akan dibahas lebih lanjut.

\section{Bahan dan metode}

Bahan yang digunakan yaitu kawat besi dan kawat aluminium lunak dengan variasi diameter dari $1 \mathrm{~mm}$ hingga $5 \mathrm{~mm}$. Selain itu, digunakan juga kawat bendrat atau kawat ikat besi dan kawat tembaga dengan diameter $1 \mathrm{~mm}$ dan $2 \mathrm{~mm}$ sebagai kombinasi.

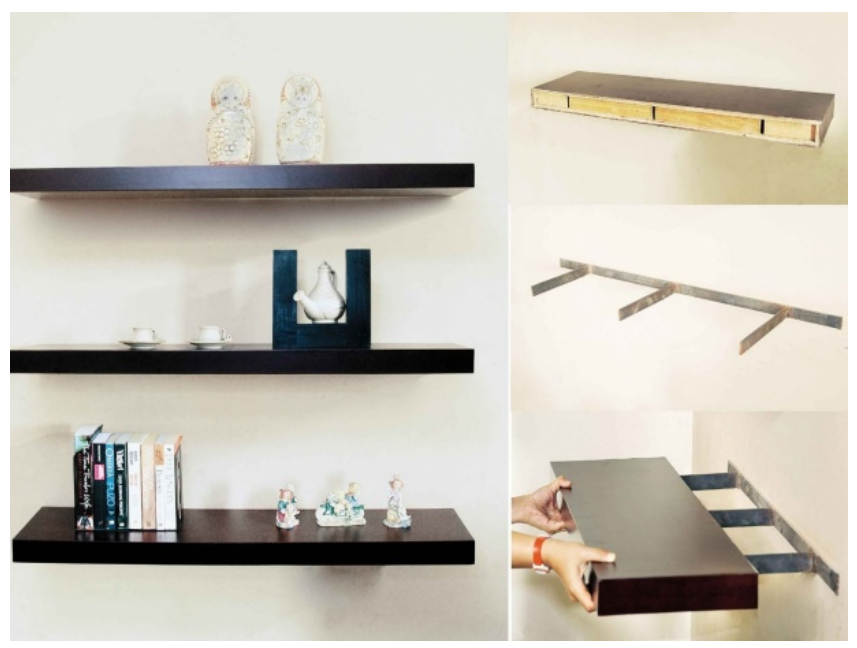

Gambar 1. Ambalan dengan Angkur Sumber: http://www.peluangproperti.com

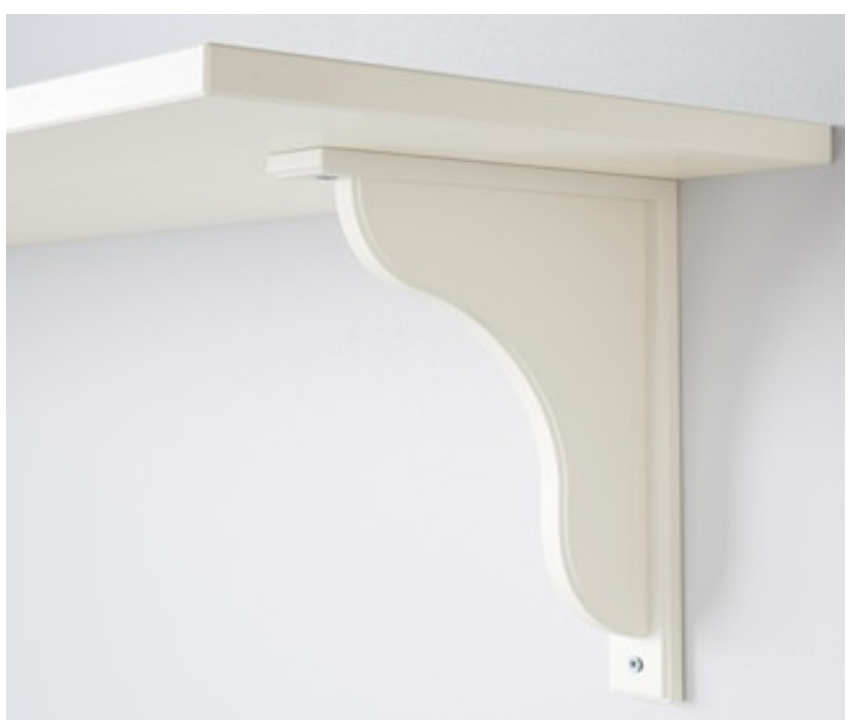

Gambar 2. Ambalan dengan Siku Penahan Sumber: https://archiwum.allegro.pl

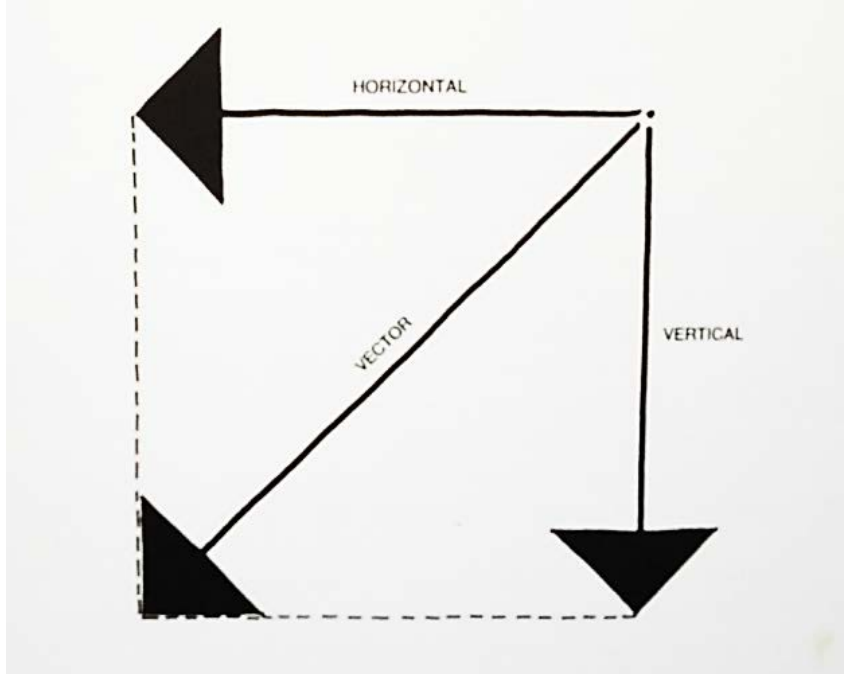

Gambar 3. Gaya Vektor (Resultan) Sumber: Rupp dkk, 1989

Metode yang digunakan adalah eksperimen dengan penekanan pada struktur kekuatan kawat dalam menahan beban, serta eksplorasi desain dengan teknik olah kawat yaitu puntir (twisting), lilit (coiling), spiral, dan pembengkokan (bending). Olah kawat dilakukan dengan menggunakan alat tang. Uji beban dilakukan dengan tujuan untuk mengetahui kekuatan struktur kawat sebagai ambalan. Pengujian dilakukan dengan memberikan beban berupa buku dengan total berat mencapai $10 \mathrm{~kg}$. Hal ini dilakukan dalam pembelajaran pada mata kuliah Desain Produk 1.

\section{Hasil dan pembahasan}

Pembebanan pada suatu bidang akan menghasilkan gaya aksi dan reaksi yang besarnya sama. Suatu bidang yang ditekan akan memiliki gaya pada sumbu x (horizontal) dan pada sumbu y (vertikal). Gaya-gaya yang bekerja tersebut menghasilkan suatu resultan gaya, seperti pada ilustrasi Gambar 3.

Desain suatu rangka struktur batang untuk menahan suatu beban, perlu memperhatikan beberapa aspek yang berkaitan dengan arah gaya tekan terkait dengan resultan gaya, regangan, tegangan geser, momen statis dan momen bengkok, yang semua mengarah pada struktur kontruksi suatu rangka.

Rangka struktur yang menerima beban memiliki kecenderungan mengalami deformasi bentuk, deformasi bentuk yang ekstrim mengakibatkan struktur tidak mampu menahan beban seperti yang diperlihatkan Gambar 4, 5, 6, 7 (Rupp, Friedmann, \& Farrell, 1989). Desain rangka struktur perlu mencapai keseimbangan agar mampu menahan beban dengan baik (Gordon, 1987). 
Selain itu, desain rangka struktur yang dibentuk juga perlu memperhatikan kriteria kekuatan tarik (tensile strength). Kemampuan tarik akan terlihat ketika suatu rangka struktur diberikan beban. Rangka struktur yang kuat akan mendistribusikan beban secara merata sehingga tetap bertahan dalam posisinya walaupun diberi beban berat. Sebaliknya, rangka struktur yang lemah kekuatan tariknya akan mengalami patah atau putus.

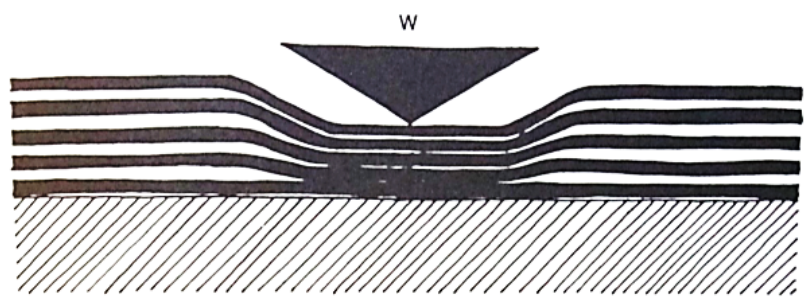

Gambar 4. Tegangan Tekan

Sumber: Rupp dkk, 1989

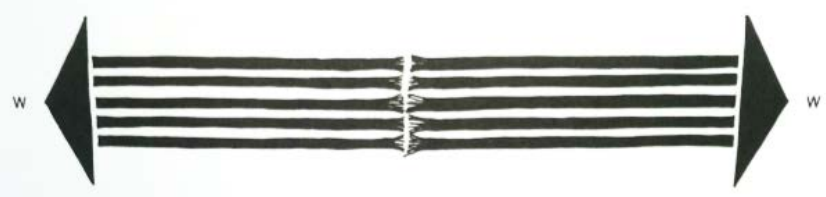

Gambar 5. Kuat Tarik

Sumber: Rupp dkk, 1989

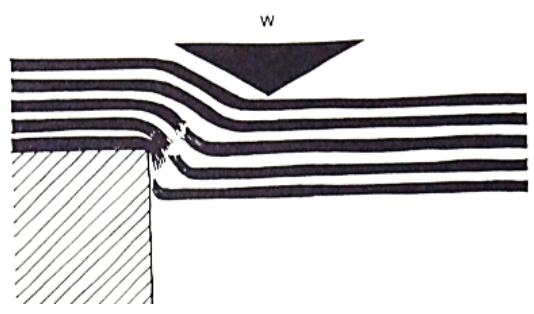

Gambar 6. Vertical Shear

Sumber: Rupp dkk, 1989

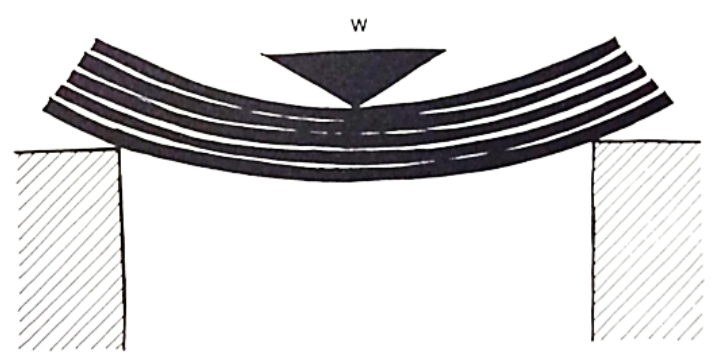

HORIZONTAL SHEAR

Gambar 7. Horizontal Shear

Sumber: Rupp dkk, 1989

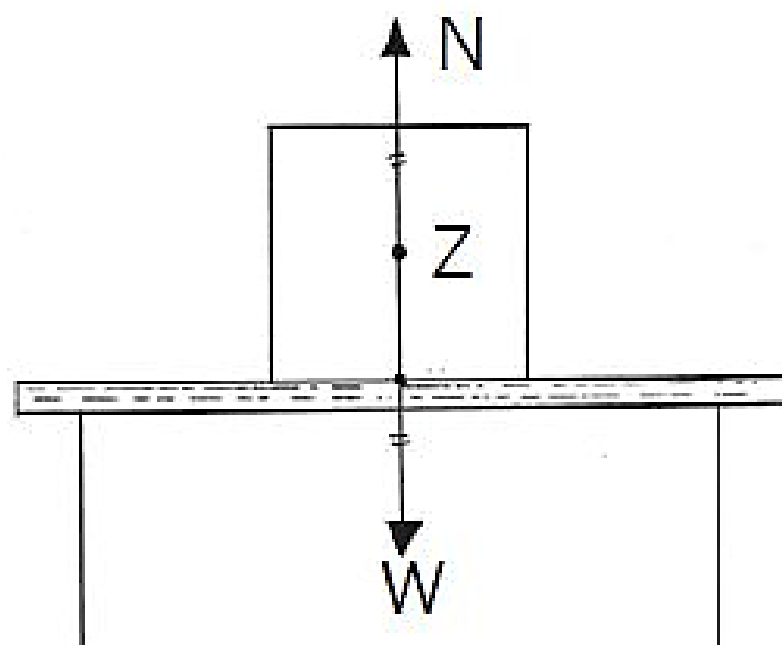

Gambar 8. Gaya Berat yang Bekerja Sumber: Rupp dkk, 1989

Untuk mengetahui kekuatan suatu struktur, maka kriteria lain yang perlu diperhatikan adalah tegangan dan regangan. Keduanya mempengaruhi bagaimana beban bekerja terhadap suatu bahan struktur. Besarnya tegangan pada sebuah rangka struktur ditentukan dari perbandingan antara gaya tarik yang bekerja pada suatu struktur terhadap luas penampang struktur tersebut (Gere, 2006). Menurut Heinz Frick, terdapat dua jenis tegangan yaitu tegangan normal dan tegangan geser. Tegangan normal adalah tegangan yang bekerja dalam arah tegak lurus permukaan bidang sedangkan tegangan geser (shear stress) tegangan yang terjadi akibat ada dua arah gaya yang berlawanan dan tidak lurus bidang suatu benda (Frick, 1984). Tegangan geser dipengaruhi oleh vertikal dan horizontal shear. Apabila suatu rangka struktur diberi beban secara meningkat atau dalam jangka waktu lama, maka struktur tersebut akan meregang. Apabila rangka struktur tidak cukup kuat, maka akan terjadi deformasi. Arah deformasi ini bisa ke arah vertical maupun horizontal.

Pada tahap pengujian kekuatan struktur rangka, digunakan papan sebagai bidang permukaan tempat meletakan beban. Beban yang diletakkan di atas papan akan menimbulkan gaya berat (W) yang muncul akibat adanya gaya gravitasi (g) dan massa beban $(\mathrm{m})$, sedangkan gaya normal $(\mathrm{N})$ adalah gaya yang bekerja pada dua benda yang saling bersentuhan. Dalam hal ini, gaya normal bekerja pada beban berupa buku dan papan ambalan. Arah gaya normal tegak lurus permukaan bidang sentuh, sedangkan arah gaya berat tegak lurus ke bawah menuju pusat bumi.

Papan yang tidak kuat menahan beban juga akan mengalami perubahan permukaan (deformasi) karena 
adanya momen lentur (Gambar 9) yang muncul. Papan untuk menguji struktur harus dipilih papan yang memiliki ketahanan lentur yang baik. Desain struktur kawat pada Gambar 10 dibuat dengan menggabungkan tiga kawat besi berdiameter 1,5 mm yang masing-masing telah dipuntir dengan kawat berukuran sama.

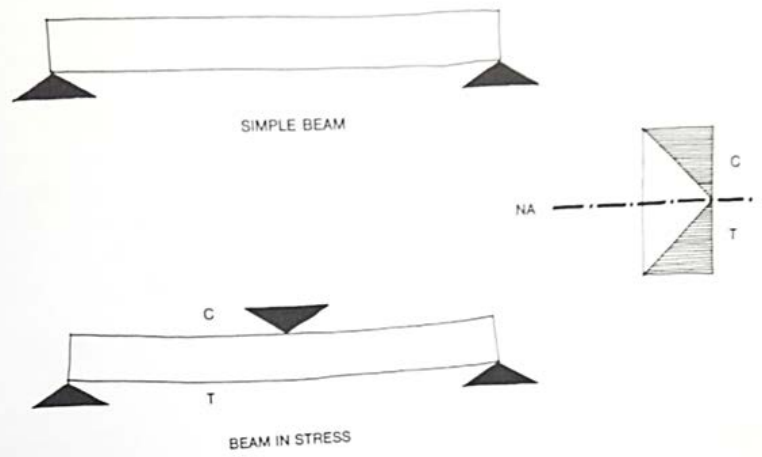

Gambar 9. Balok dengan dan Tanpa Gaya Tekan Sumber: Rupp dkk, 1989

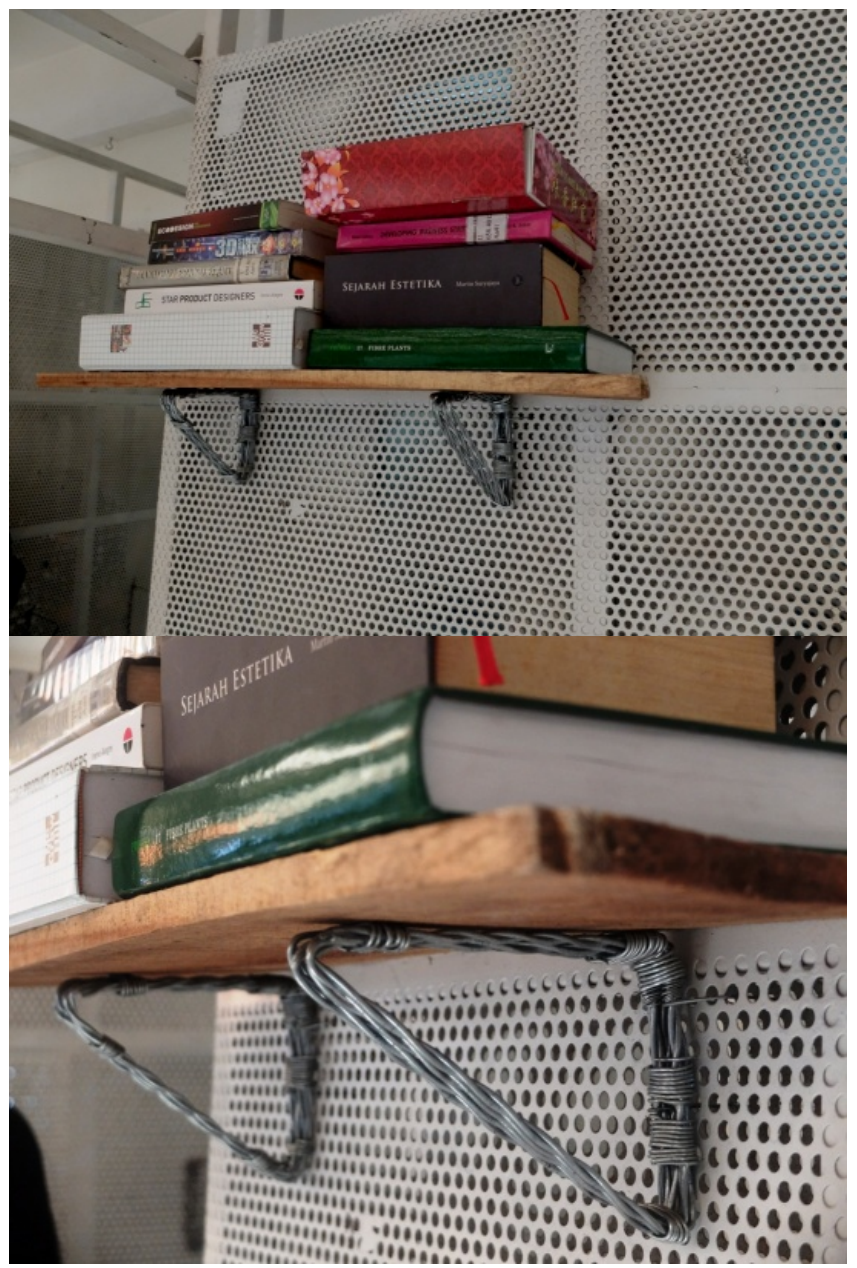

Gambar 10. Desain struktur kawat karya Chornelius Anantya Sumber: Christmastuti Nur, 2018
Desain struktur kawat ini mampu menahan beban seberat $10 \mathrm{~kg}$ dengan stabil dan tidak mengalami deformasi dalam jangka waktu lama. Kekuatan desain struktur ini terletak pada kemampuannya dalam mendistribusikan beban baik ke arah vertikal maupun horizontal (lihat Gambar 3). Akibatnya arah gaya berat beban pada bidang permukaan dapat tegak lurus ke bawah. Kekuatan dan kekokohan dalam desain struktur ini juga mampu membangkitkan kepercayaan pengguna atau konsumen. Desain struktur kawat pada Gambar 11 dibuat dengan menggabungkan dua kawat besi berdiameter $3 \mathrm{~mm}$ dengan teknik puntir. Desain struktur kawat ini juga mampu menahan beban seberat $10 \mathrm{~kg}$ dengan stabil dan tidak mengalami deformasi dalam jangka waktu lama. Desain struktur pada Gambar 11 memiliki kelebihan yaitu efiensi penggunaan bahan.

Selain desain struktur pada Gambar 11, desain struktur pada Gambar 12 juga memiliki keunggulan dalam hal efisiensi penggunaan bahan. Kawat yang digunakan pun relatif berdiameter lebih kecil yaitu kawat berdiameter $1,5 \mathrm{~mm}$ yang dipuntir dengan kawat berdiameter 1,5 $\mathrm{mm}$ tanpa puntiran.

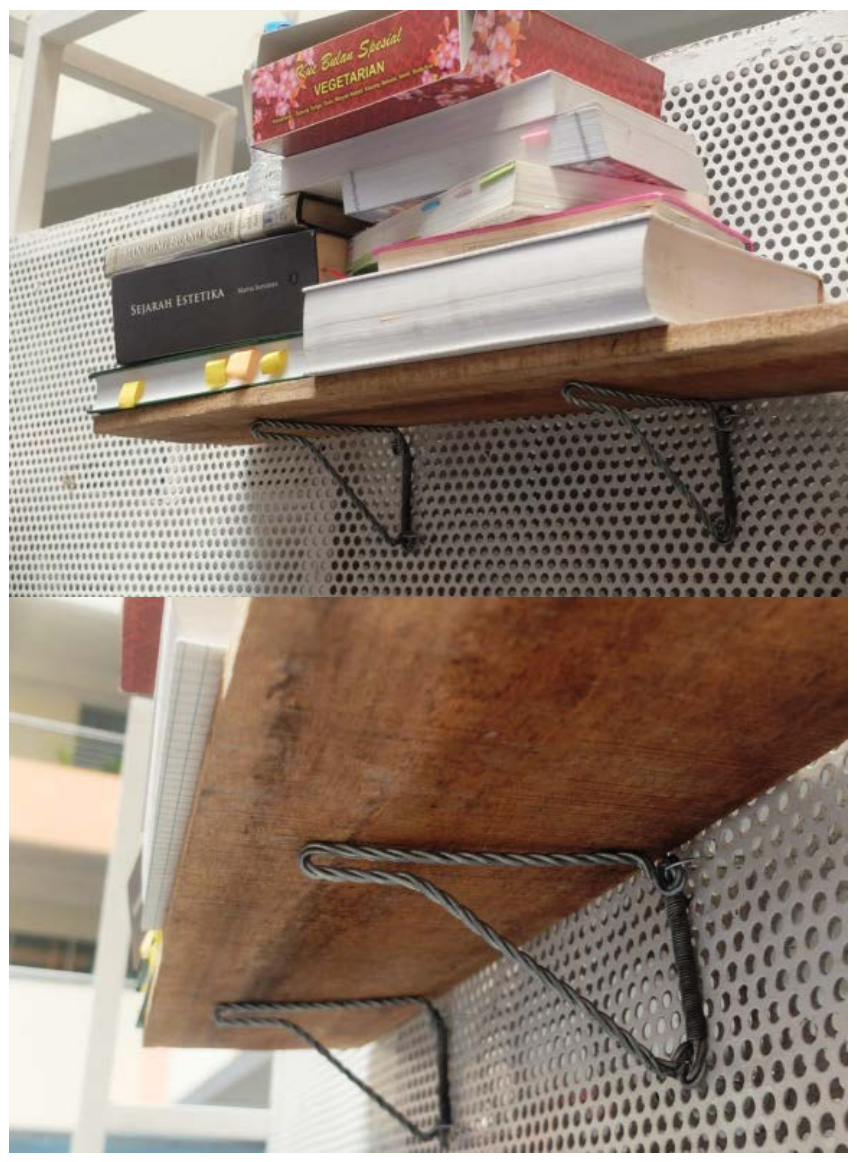

Gambar 11. Desain Struktur Kawat Karya Andrean Tandi Sumber: Christmastuti Nur, 2018 


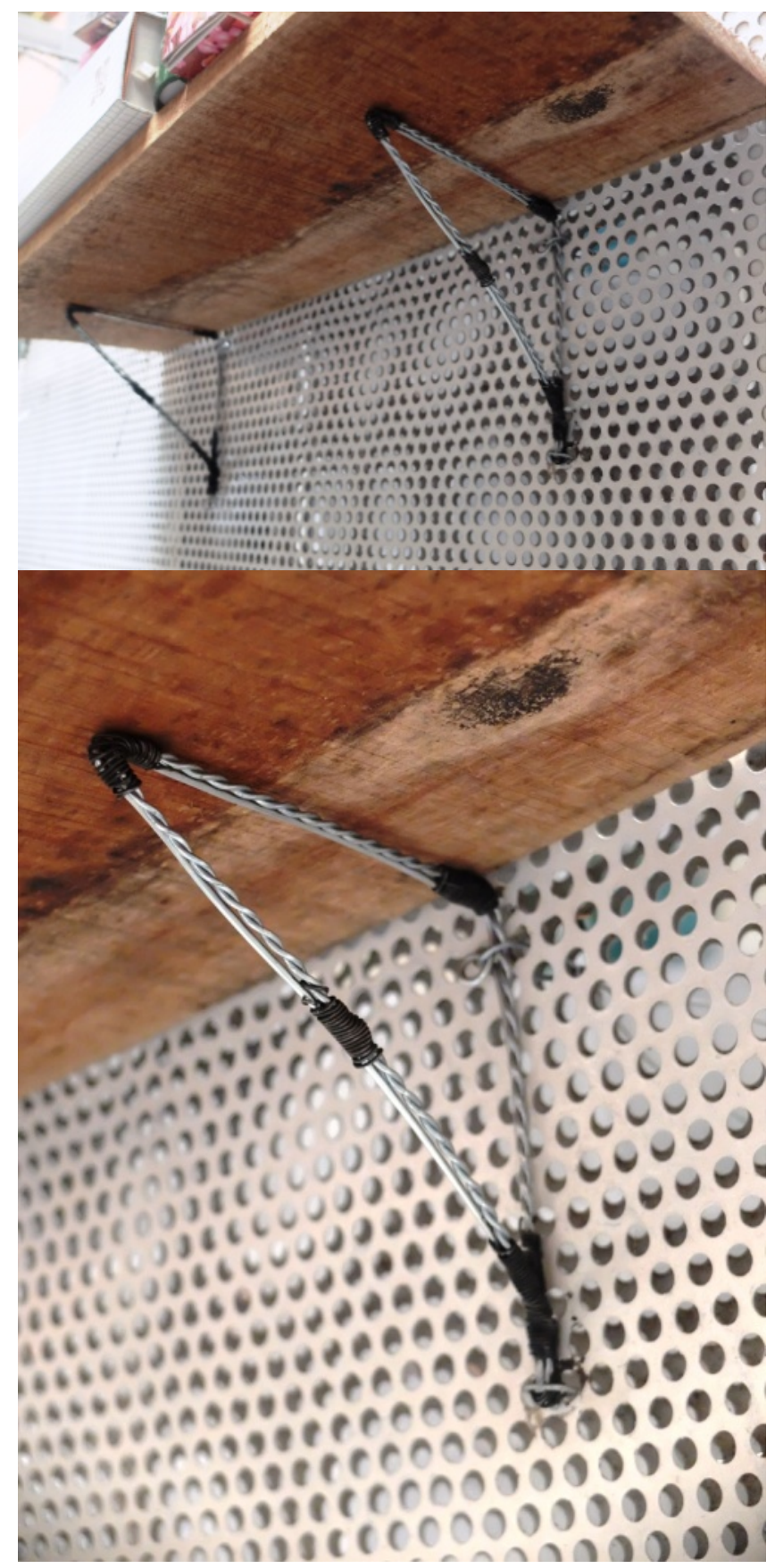

Gambar 12. Desain struktur kawat karya Zipora Kossay Sumber: Christmastuti Nur, 2018

Dalam segi estetika, ketiga desain yang telah disebutkan ini menunjukkan keunikan dan keindahannya melalui teknik olah kawat puntir (twisting) yang memunculkan kesederhanaan bentuk dan warna (contoh: hanya menggunakan satu jenis warna kawat), maupun melalui permainan warna jenis kawat (contoh: kombinasi kawat besi dengan kawat bendrat).

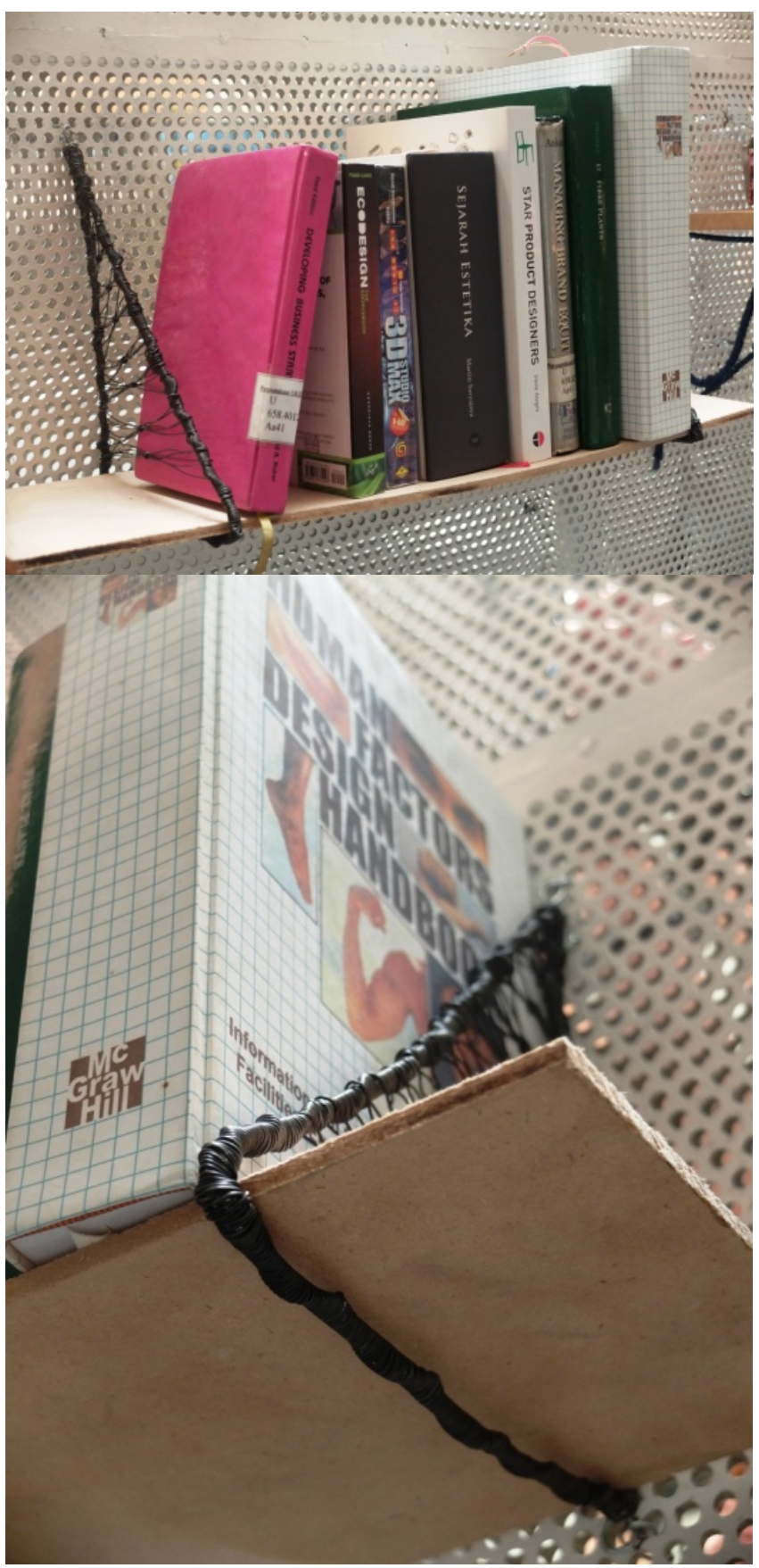

Gambar 13. Desain Struktur Kawat Karya Alexandra Sede Sumber: Christmastuti Nur, 2018

Berbeda dengan desain struktur sebelumnya, desain struktur pada Gambar 14 tidak meletakkan bidang datar penyangga beban di atas struktur rangka tapi diselipkan. Desain rangka ini juga menambahkan isian yang bertujuan sebagai elemen estetis pada selasela atau rongga antara kawat posisi vertikal dan kawat posisi diagonal. Walaupun demikian, desain struktur pada Gambar 12 dan Gambar 13 memiliki kemampuan menahan beban yang sama dengan 
desain struktur pada Gambar 10 dan Gambar 11. Keempat desain ini mampu menahan beban sebesar $10 \mathrm{~kg}$ secara stabil dan tidak mengalami deformasi. Analisis lebih mendalam, menunjukkan bahwa keempat desain memiliki kemiripan struktur yaitu pada rangka yang berbentuk segitiga.

Desain struktur yang lain ditunjukkan pada Gambar 14 dan Gambar 15, yang menggunakan teknik olah kawat puntir (twisting) kemudian dililit (coiling) dengan kawat tembaga yang membedakan dari desain struktur sebelumnya. Desain struktur pada Gambar 14 terdiri dari dua elemen utama yaitu kawat dengan arah horizontal dan kawat dengan arah diagonal, sedangkan pada Gambar 15, desain struktur terdiri dari tiga elemen yaitu kawat dengan arah horizontal, kawat dengan arah diagonal, dan kawat dengan arah vertikal, namun tidak tegak lurus. Ketika pengujian beban, desain struktur pada Gambar 14 mampu menahan beban seberat $10 \mathrm{~kg}$ secara stabil, namun tidak dalam jangka panjang. Hal ini disebabkan tidak adalanya elemen kawat dengan arah vertikal yang membantu menopang beban, seperti pada empat desain yang telah ditunjukkan sebelumnya (bandingkan dengan prinsip gaya pada Gambar 3). Akan tetapi, desain struktur pada Gambar 15 walaupun terdiri dari tiga elemen namun tidak stabil dan tidak dapat menahan beban dalam waktu lama. Penyebabnya adalah setiap elemen kawat tidak tegak lurus sehingga tidak sempurna dalam menahan beban.

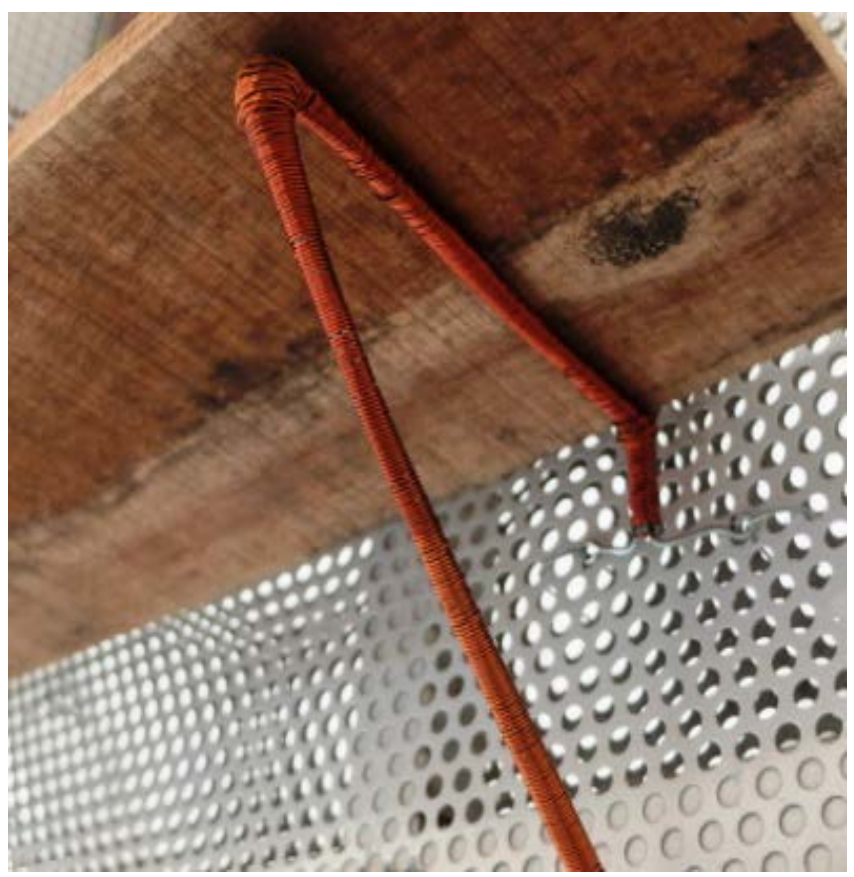

Gambar 14. Desain Struktur Kawat Karya Pic Yen Sumber: Christmastuti Nur, 2018

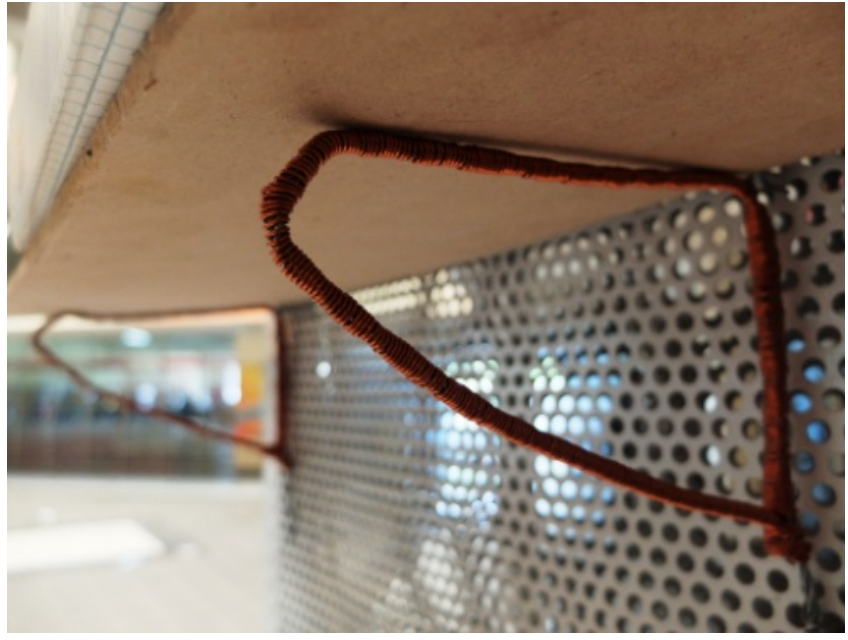

Gambar 15. Desain Struktur Kawat Karya Bridget Anabelle Sumber: Christmastuti Nur, 2018

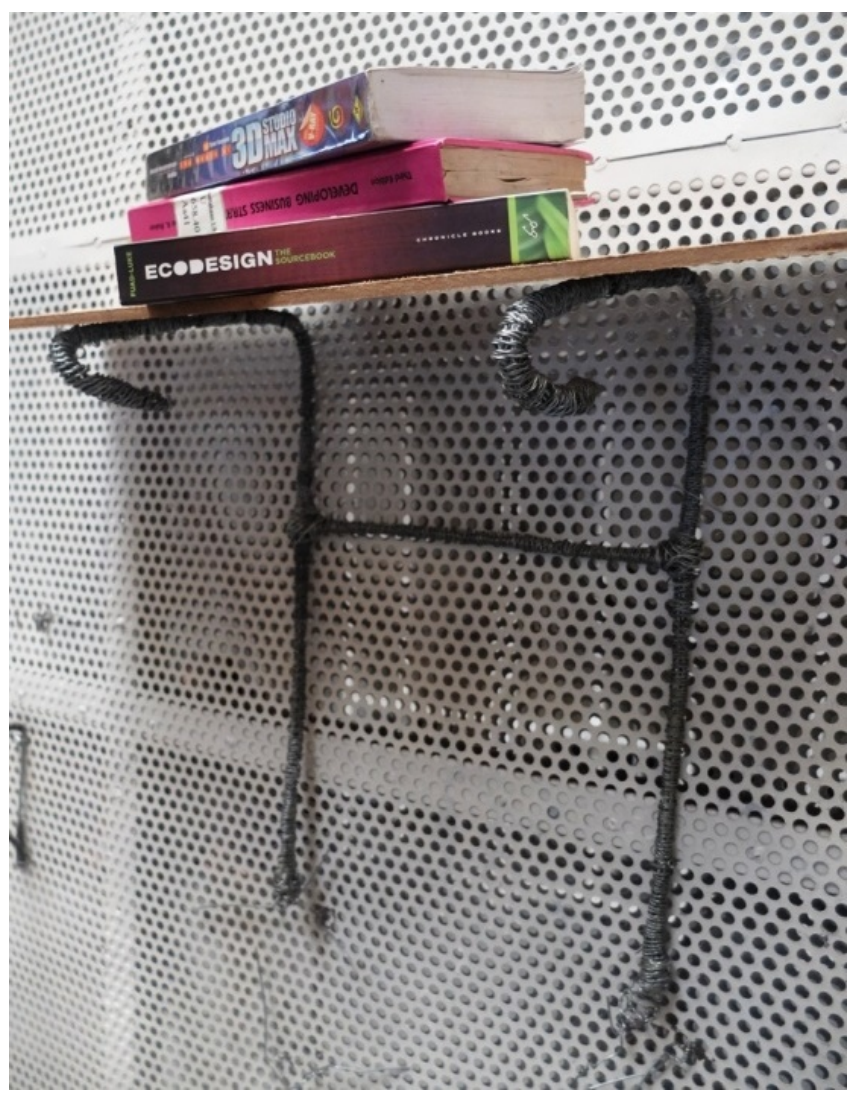

Gambar 16. Desain Struktur Kawat Karya Hanna Gloria Sumber: Christmastuti Nur, 2018

Hal yang serupa dijumpai pada desain struktur dalam Gambar 16 yang menggunakan gabungan beberapa kawat berdiameter $2 \mathrm{~mm}$ lalu dililit (coiling). Distribusi beban hanya diletakkan pada elemen kawat dengan arah horizontal, akibatnya struktur kawat mengalami deformasi dan tidak mampu menahan beban secara stabil walaupun dalam 
waktu singkat. Melalui desain pada Gambar 16 juga diketahui penggunaan jenis kawat tidak mempengaruhi kekuatan struktur. Selain itu, seharusnya penggunaan kawat ditekankan pada penguatan rangka struktur agar lebih efisien.

Desain struktur pada Gambar 17 juga sangat lemah dan mengalami deformasi berupa kemiringan saat struktur diberi beban. Walaupun demikian, desain

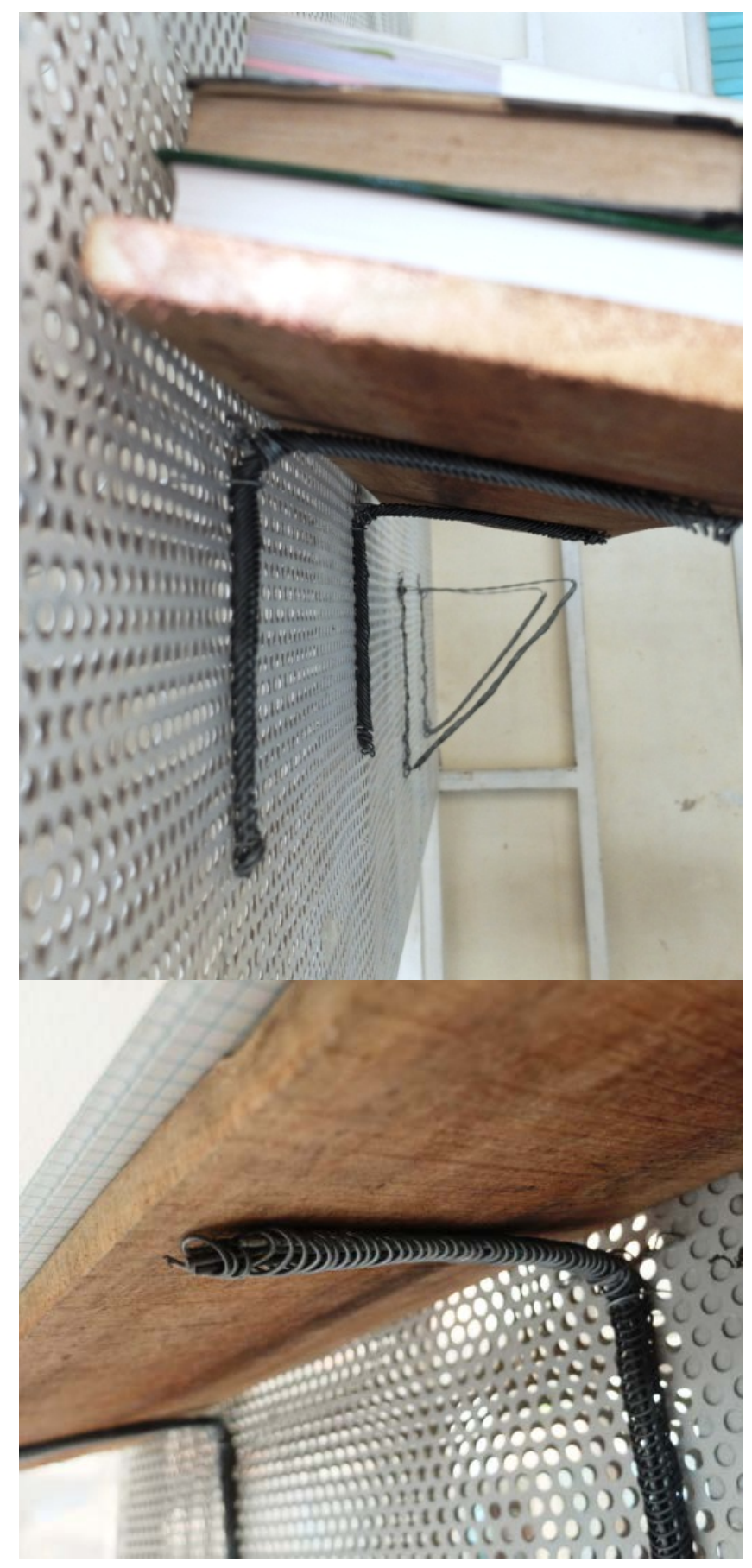

Gambar 17. Desain struktur kawat karya Aura Khyas Sumber: Christmastuti Nur, 2018 struktur ini memiliki tampilan visual yang estetis karena penggunaan teknik olah kawat yaitu penggabungan beberapa kawat berdiameter 2,5 mm yang dililit (coiling) lalu dibengkokkan dan dipipihkan (bending). Desain ini dapat dikembangkan dengan memperbaiki strukturnya yaitu dengan menambahkan elemen kawat dengan arah diagonal agar membantu dalam menopang beban. Struktur yang berbentuk segitiga seperti yang ditunjukkan dalam desain struktur pada Gambar 10, Gambar 11, Gambar 12, dan Gambar 13 terbukti lebih kuat dalam menopang beban. Hal ini disebabkan karena Pembebanan pada suatu bidang akan menghasilkan gaya aksi dan reaksi yang besarnya sama. Suatu bidang yang ditekan akan memiliki gaya pada sumbu x (horizontal) dan pada sumbu y (vertikal). Penjelasan mengenai prinsip ini terdapat pada Gambar 18 dan Gambar 19.

Struktur segitiga mampu menahan resultan gaya yang muncul akibat gaya pada sumbu $\mathrm{x}$ dan $\mathrm{y}$, karena itu struktur ini adalah struktur yang stabil. Struktur siku (L bracket) dari bahan kawat, justru kurang stabil karena tidak ada penahan pada sisi diagonal (miring).

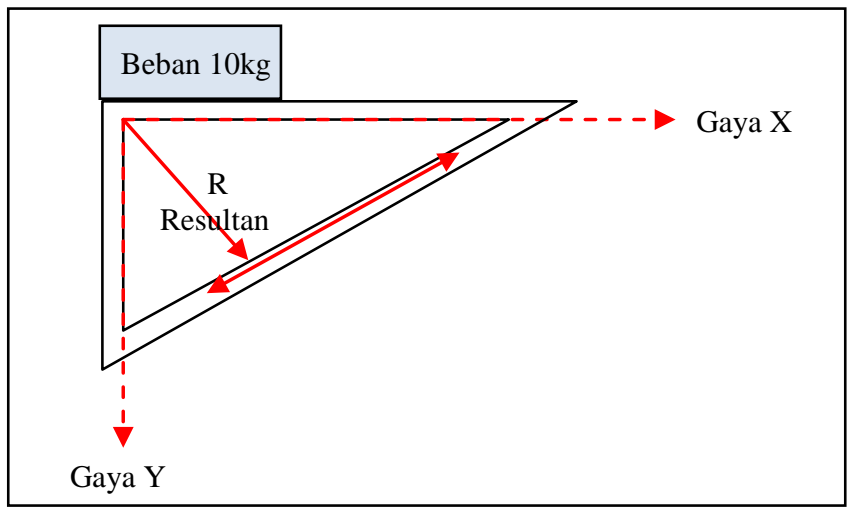

Gambar 18. Ilustrasi pembebanan struktur segitiga

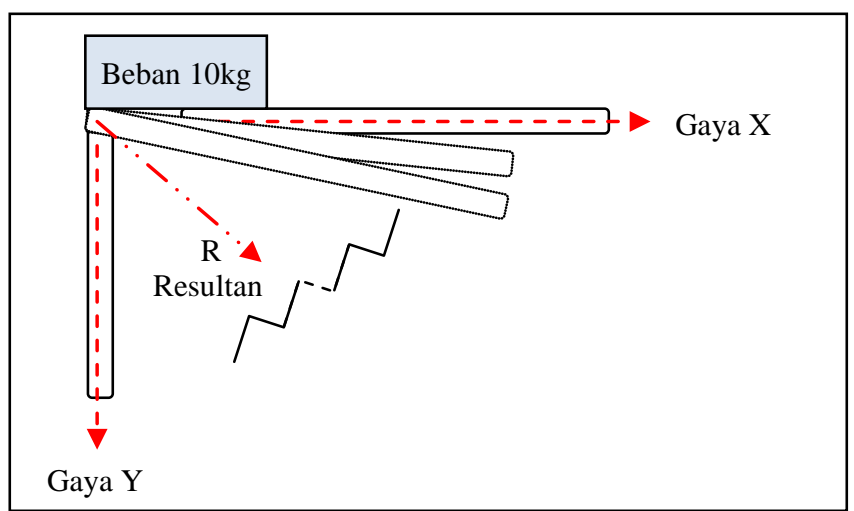

Gambar 19. Ilustrasi Pembebanan Struktur Siku 


\section{Kesimpulan}

Suatu konstruksi yang diberikan gaya tekan akan merespon dengan gaya reaksi. Gaya reaksi tersebut berupa regangan dan momen lentur yang ditentukan oleh kuat tidaknya suatu struktur. Ketahanan yang kuat pada suatu konstruksi akan menghasilkan struktur yang kuat pula, jika konstruksi lemah maka akan menyebabkan daya tahan yang lemah.

Seperti penemuan oleh Gordon, tekanan atau gaya yang diberikan tidak pernah hilang begitu saja, namun semua gaya tersebut memiliki reaksi yang berlawanan arah dengan besaran yang sama, karena itu gaya/tekanan yang ada perlu diseimbangkan (Gordon, 2009). Kemampuan menyeimbangkan gaya yang bekerja dengan memperhatikan titik tumpu maupun bentuk rangka, dapat menghasilkan konstruksi yang stabil dalam menahan beban.

Konstruksi yang paling kuat dan stabil adalah bentuk segitiga karena mampu menahan resultan gaya yang muncul akibat gaya pada sumbu $\mathrm{x}$ dan $\mathrm{y}$. Oleh karena itu, dalam mendesain struktur konstruksi sebagai penyangga ambalan yang paling baik adalah bentuk segitiga.

\section{Daftar pustaka}

Astuti, P., \& Kusno, K. (2014). Rack storage component design by parametric curves and surfaces. Jurnal ILMU DASAR, 13(1), 31-40.

Frick, H. (1984). Mekanika Teknik 2: Statika dan Kegunaannya. Yogyakarta: Penerbit Kanisius.

Gere, J. M. (2006). Mechanics of materials (6th ed.). Toronto: Thompson Publishing.

Gordon, J. E. (2009). Structures: or why things don't fall down. Cambridge, MA: Da Capo Press.

Jayadi, N., \& Prasetya, R. D. (2017). Pengembangan desain produk berbahan baku limbah kerang di Bantul. PRODUCTUM Jurnal Desain Produk (Pengetahuan Dan Perancangan Produk), 3(1).

Rupp, W., Friedmann, A., \& Farrell, P. F. (1989). Construction materials for interior design: principles of structure and properties of materials. New York: Watson-Guptill. 